\title{
INTEGRATING THE NATURAL CLIMATE REGIME INTO MANAGEMENT PLANS FOR SWINE WASTEWATER LAGOONS
}

\author{
Charles L. Wax \\ Department of Geosciences, Mississippi State University \\ Jonathan W. Pote \\ Department of Agricultural and Biological Engineering \\ Mississippi Agricultural and Forestry Experiment Station \\ Mississippi State University
}

Michael E. Brown

Department of Geosciences, Mississippi State University

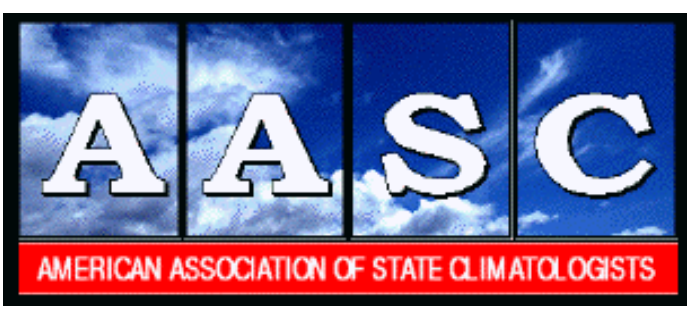

2008

Journal of Service Climatology

Volume 2, Number 4, Pages 1-10

A Refereed Journal of the American Association of State Climatologists 


\title{
Integrating the Natural Climate Regime Into Management Plans for Swine Wastewater Lagoons
}

\author{
Charles L. Wax \\ Department of Geosciences \\ Mississippi State University \\ Jonathan W. Pote \\ Department of Agricultural and Biological Engineering \\ Associate Director, Mississippi Agricultural and Forestry Experiment Station \\ Mississippi State University \\ Michael E. Brown \\ Department of Geosciences \\ Mississippi State University
}

Corresponding author: Charles L. Wax, Office of the Mississippi State Climatologist, PO Box 5448, Mississippi State, MS 39762, USA. Tel. 1-662-325-3915, wax@geosci.msstate.edu.

(Non-technical summary is at the end of this paper)

\begin{abstract}
Disposal of wastewater from large-scale swine production facilities in the southern region of the U.S. is increasingly problematic as production facilities increase and regulations governing disposal become more restrictive. No-discharge systems are attractive or even mandatory for many producers. In such systems, wastewater is pumped from a storage lagoon when a certain level of storage is reached, and proper disposal depends on evaporation, infiltration into the soil, and on a crop's ability to utilize some nutrient such as nitrogen or phosphorus at that time. Under the control of climate in the region, lagoon levels rise during periods of precipitation while the soil becomes wet and the net water requirement of plants decreases, precluding irrigation. Wastewater volume is therefore typically high during winter and spring when pumping would be ecologically damaging, and low during summer and fall when conditions are more often suitable for successful land application. Consequently, at the moment of greatest need this type of disposal system is not operational, and spills or illegal discharges may occur. This study uses daily computer simulation over a 45-year period to test how well five management strategies could remedy this offset distribution of wastewater supply and demand. Pumping once each year on planned dates of the $15^{\text {th }}$ of June, July, August, and September do successfully shift the time of necessary pumping out of the winter and spring and into the growing season. An annual September $15^{\text {th }}$ pumping of lagoons is recommended as the most efficient management plan for avoiding illegal overflows and emergency pumpings at times when land application will not be successful.
\end{abstract}




\section{Introduction}

The humid sub-tropical climate of the southeastern United States is characterized by temperate winters, abundant radiation and consequent high temperatures and evaporation rates in summer, and rainfall more or less evenly distributed throughout the year. These climatic attributes strongly influence environmental and economic activities, and thereby establish opportunities and constraints for human use of the region. Adjustment to this climatic setting has led to the present arrangement of agricultural and forestry practices and other land use patterns and resource use considerations.

Production of animals is particularly suited to this region's climate. Beef, poultry, and catfish have proven to be economically viable and have continued to grow in importance. All these activities are noted as potential causes of non-point source pollution with increasing regulations to control them (CAST 1996). Changes in swine production methods resulting in highly concentrated facilities have rapidly begun to appear in the region.

Disposal of wastewater from swine production is becoming an increasing problem as production facilities increase and regulations governing disposal become more restrictive. The option of no-discharge systems has become attractive or even mandatory for many of these swine producers, especially in regions where disposal opportunities are limited or for those producers newly entering the undertaking (Martin 1995). These systems use a lagoon with land application of waste as the final stage to treat effluent (Loehr 1984). Typically, wastewater is pumped from the lagoon when a certain level of storage is reached, and proper disposal depends on evaporation, infiltration into the soil, and on a crop's ability to utilize some nutrient such as nitrogen or phosphorus at that time.

Climatic characteristics in many ways dominate considerations for land application. However, incorporating climate into design and management of this type of disposal method for swine waste has been limited to sizing the lagoons large enough to carry producers through the longest expected wet season, essentially an entire year. Operating the lagoon to provide storage space when climatological conditions preclude pumping has largely been ignored in management strategies, or the bases for such attempts have been unavailable. Studies related to aquaculture ponds in the southern region, however, have shown the effectiveness of managing water levels to reduce overflow and consequent release of effluent into the environment. Cathcart, et al. (2007) tested management strategies for catfish ponds based on allowing the water levels to drop by evaporation and therefore making storage space available for the ponds to capture and hold subsequent precipitation. They reported reductions of overflow across the region ranging from $50-75 \%$.

In a land application system the level in the lagoon rises during periods of precipitation while the soil becomes wet and the net water requirement of plants decreases, thwarting irrigation. Consequently, at the moment of greatest need this type of disposal system is not operational, and spills or illegal discharges may occur. In fact, $88 \%$ of all factory hog farms had at least one permit or waste management plan violation in 1997 (Environmental Defense 2002). Conversely, during periods of clear weather the level in the lagoon may drop from evaporation, the soil will become dry and the water requirements of plants are immediate, allowing proper disposal of the wastewater. Therefore, the climate may establish a pattern in which the supply of water to be disposed of and the waterconsuming capabilities of plants, the atmosphere, and soil are out of phase. As a result, a climatological analysis can provide management considerations to enhance the usefulness of the land application disposal method.

The objectives of this research were to:

1) develop analyses that account for climatological effects on design and performance of land application of swine lagoon effluent;

2) derive management strategies based on these climatological effects and demonstrate the impact of these strategies by computer simulation; and

3) define the optimum management strategies and probabilities of failures while employing these strategies in waste disposal.

\section{Background}

Irrigation is the predominant method of choice for land application, even for municipal wastewater (Deese and Hudson 1980). However, those municipal systems are designed for daily irrigation of effluent when possible (Pote and Wax 1995). The Natural Resources Conservation Service of the U.S. Department of Agriculture (NRCS) designs swine lagoon irrigation systems for pumping of the wastewater as seldom as once a year (NRCS 1996, 1993).

The lagoon and application system used in the simulations for this study were based directly on an actual design completed for operation in Mississippi by NRCS. The system was designed for a facility housing 3520 swine with an average weight of $61 \mathrm{~kg}$ (135 pounds) each. In this design, a constant daily volume of $30 \mathrm{~m}^{3}$ (1037 $\mathrm{ft}^{3}$ ) of wastewater was transferred to the treatment facility via slotted floors over pits. The design volume of the lagoon was 25,700 $\mathrm{m}^{3}(908,064$ $\mathrm{ft}^{3}$ ), with surface area dimensions of 137 X $88 \mathrm{~m}$ 
(450 X 290 feet). Based on waste flow and precipitation, the system was designed with an application rate of $14,600 \mathrm{~m}^{3}\left(515,623 \mathrm{ft}^{3}\right)$ over 24 ha (61 acres), or $58 \mathrm{~mm} / \mathrm{ha}$ (2.3 inches/acre), as determined by total nitrogen concentration. The frequency of application was designed for irrigation occurring when the lagoon filled, only once per year most of the time.

Much of the literature concerning land application systems has been devoted to determining the fate of the nutrients (Barbarick, et al. 1982; Palazzo, 1981; Thoma, et al. 1993; Mancino and Pepper 1992). Nutrient analysis is also an integral part of the design of irrigation systems for swine lagoon effluent (NRCS 1993). While design based on nutrient loading alone has been acceptable for arid climates, when this method of disposal is considered in humid areas the water balance and other climate characteristics of the region become the dominant factors in operation of these systems (Midwest Plan Service 1985). Al-Omari (1989) examined probabilistic design options based on five years of data in Texas, producing results in terms of field size and holding pond size for municipal disposal systems. Wax and Pote (1996) expanded this probabilistic approach to include longer periods of data and several climate regimes.

Poor management decisions and methods may result in long-term, chronic problems related to nutrient disposal, but the immediate and dramatic failures with the lagoon and land application system are related primarily to water issues. For example, lagoons typically are too full in the winter season, with only two alternatives: a catastrophic spill event, or a forced pumping at a time when neither the plants nor the soil can accept the water.

An active management plan that prevents lagoons being full at the wrong time of the year is needed so that maximum use can be made of both the water and nutrients during land application. The performance of such a management plan can be evaluated by modeling the system in daily operation, determining the incidence and severity of failure, and testing management alternatives.

\section{Methodology}

\section{a. Simulation of daily water level and pumping requirement}

Daily precipitation (P) and pan evaporation (E) data from State University, Mississippi, were obtained from observations of the Cooperative Network of the National Weather Service. This location was representative of the southern region climate and had the most complete record of the climatic elements needed for the simulation. A factor of $0.8 \mathrm{E}$ was used to correct measured $\mathrm{E}$ to a more realistic estimate of evapotranspiration losses (ET) from small bodies of water or lagoons (Schwab, et al. 1981). On a daily basis, this climatic demand for water (ET) might be partially or totally satisfied by $\mathrm{P}$ and incoming wastewater (W), and an increase in volume could even result if $\mathrm{P}+\mathrm{W}$ was greater than ET that day. On days with little or no $\mathrm{P}$, there would be a water deficit (P-ET) which could cause the lagoon level to drop, depending upon the amount of $\mathrm{W}$ arriving-a constant daily volume of $30 \mathrm{~m}^{3}\left(1037 \mathrm{ft}^{3}\right)$.

Daily computation of P-ET+W was conducted for the 45-year period 1961-2005 to simulate the operation of a lagoon purely under the influence of climate. Cumulative summation of these daily values provided patterns of water volume in a lagoon allowed to overflow in lieu of planned pumpings. This volume and pattern of discharge would be analogous to that occurring when no land application of effluent was attempted, and thus represents a "no management" situation in which a full lagoon simply leaked or trickled effluent into the surrounding environment.

In order to test various management options, the daily simulation computations were modified to model resulting wastewater volume in the lagoon when land application by pumping of effluent (A) was incorporated into operation of the system. The model was constructed to let the volume of wastewater in the lagoon determine when pumping occurred as follows: $\mathrm{V}=\mathrm{P}-$ $\mathrm{ET}+\mathrm{W}-\mathrm{A}$, where

$$
\begin{aligned}
& \mathrm{V}=\text { initial volume of wastewater in the lagoon } \\
& \mathrm{P}=\text { water gain by precipitation into the lagoon } \\
& \mathrm{ET}=\text { water loss by evapotranspiration from } \\
& \text { the lagoon } \\
& \mathrm{W}=\text { water gain by wastewater inflow } 30 \mathrm{~m}^{3} \\
& \quad\left(1037 \mathrm{ft}^{3}\right. \text { daily) } \\
& \mathrm{A}=\text { water loss by pumping from the lagoon. }
\end{aligned}
$$

Using a maximum lagoon volume of 25,700 $\mathrm{m}^{3}\left(908,064 \mathrm{ft}^{3}\right)$, the model was set to pump out $14,600 \mathrm{~m}^{3}\left(515,623 \mathrm{ft}^{3}\right)$ whenever the volume exceeded $25,200 \mathrm{~m}^{3}\left(890,000 \mathrm{ft}^{3}\right)$. This particular scenario represented a plan to pump only when the lagoon was full--a "pump when full" management strategy. Results of this model were used to determine:

1) the day-by-day volume in the lagoon over the 45-year period;

2) the number of times the lagoon filled and and had to be pumped during that period;

3) the month in which the pumpings were necessary.

Four additional management strategies which employed "fixed-date" pumpings from the lagoon on one specific date each year were tested with consequent runs of the model. Dates selected were the 15th day of June, July, August, and September. Under these strategies, the model was set to pump either $14,600 \mathrm{~m}^{3}\left(515,623 \mathrm{ft}^{3}\right)$ or $80 \%$ of that day's volume, whichever was less, on 
these dates only. An additional pumping was conducted if the lagoon volume reached 25,200 $\mathrm{m}^{3}\left(890,000 \mathrm{ft}^{3}\right)$ at any other time during the year. Results of these model runs were used to determine for all four strategies:

1) the day-by-day volume in the lagoon over the 45-year period;

2) the number of times the lagoon filled and had to be pumped on a "when full" or "emergency" basis in addition to each planned annual pumping during the period;

3) the month in which the emergency pumpings were necessary; and

4) the resulting total number of pumpings conducted over the period.

Several assumptions were included in this model. First, the entire model was based on the NRCS plan for an actual swine lagoon in Mississippi, resulting in the specific values used to determine pumped amounts of water and nutrients. In addition, the plan specified that the waste generated over an entire year would be stored and then pumped at one time. Second, pumpings in the management options modeled were conducted on the dates indicated by the simulations regardless of weather conditions at that time. Third, loss of wastewater by infiltration from the lagoon was not addressed in the model. This makes the model more conservative and more accurate for low infiltration soils.

\section{b. Analyses of simulated record}

Analyses of the "no management" situation consisted of determining patterns of average monthly overflow volume and total annual overflow for the period using results of the simulations. The number of days on which overflow occurred in each year was also determined.

Analyses of the "pump when full" management strategy consisted of determining the number of pumpings each month over the 45-year period. Additionally, probabilities of the volume in the lagoon on the first of each month were determined. This was done by extracting the simulated volume on the first of each month for each of the 45 years and then ranking these 45 numbers in descending order to establish probabilities by quantiles.

Analyses of the "fixed-date" pumping management strategies consisted of determining the number of unplanned ("emergency") pumpings in addition to the one annual planned event over the 45-year period, and the month of occurrence of the emergency pumpings. Also, probabilities of the volume in the lagoon on the first of each month were determined in the same manner as above.

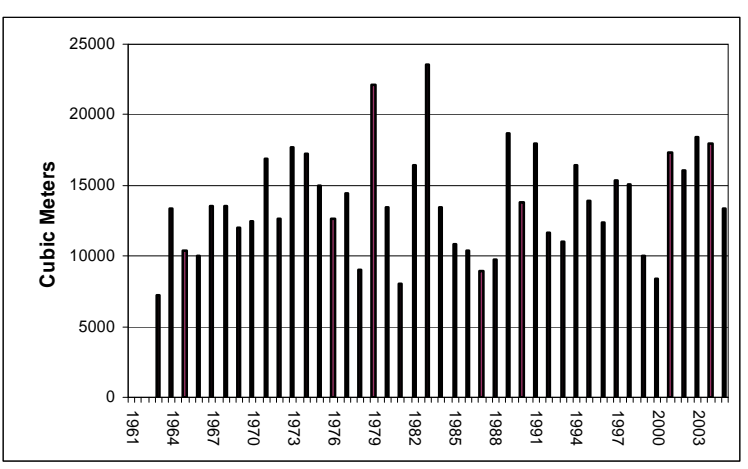

Figure 1. Average annual overflow volume 1961-2005, no management

\section{Results and Discussion}

Results of the "no management" analysis document the regional climate's potential to influence, naturally, the annual total volume of overflow (Figure 1) and the monthly average volume of overflow and the corresponding number of days on which it occurred each month (Figure 2). The results show that in an unmanaged system, overflow occurs on an average of 142 days per year with an average annual volume of $13,945 \mathrm{~m}^{3}\left(492,452 \mathrm{ft}^{3}\right)$. For perspective, it is noted that in the wettest year (1983) the number of days of overflow was relatively high (168), but the amount of overflow was remarkably higher 23,804 $\mathrm{m}^{3}\left(840,640 \mathrm{ft}^{3}\right)$. Even in the driest year (1981) overflow occurred on 122 days with a total volume of $8,088 \mathrm{~m}^{3}$ $\left(285,637 \mathrm{ft}^{3}\right)$. Therefore it is virtually certain that lagoons will overflow in large amounts each year in this climate regime.

The pattern of overflow in a system thus controlled only by climate in the natural setting of this region is shown in Figure 2. This is a very distinctive pattern, closely tied to the regional PE regime which dictates that the largest amounts of overflow from lagoons will occur in the winter and spring months with much lesser amounts

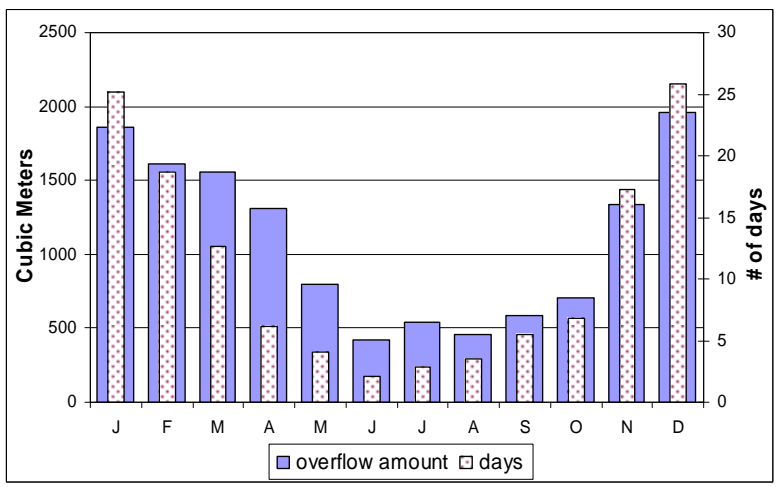

Figure 2. Average monthly overflow volume and number of days 1961-2005, no management 
expected in summer and fall. It is notable that large amounts of overflow are produced during spring months (March, April, May) with relatively few days of overflow, indicating the likelihood of large rain events during this time of year. Assuming that the effluent is to be applied to a growing crop, the distribution of available water through the year is diametrically opposed to the pattern of crop need. Corn is an example of a crop likely to be used in the southern region for land application of wastewater, and its pattern of water need, mainly May through August, is typical of other crops in the south (Figure 3 ). This conflict in timing between demand and supply is therefore the basis of a management problem in land application of animal waste in the humid subtropical climate region.

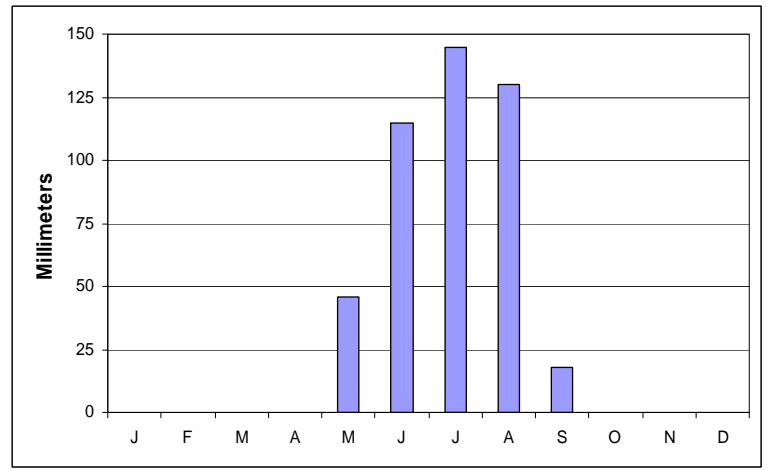

Figure 3. Monthly water need, corn, 10 May emergence date

In the simplest management system, "pump when full", lagoons do not overflow but are pumped when they fill to a certain level, occurring about once a year. This minimizes the number of pumpings required, but does nothing to address the above problem. Figure 4 shows results of the 45-year simulation of this management plan. The pattern of required pumpings in the figure follows the same distribution in time as the unmanaged system-they all come during winter and spring when the

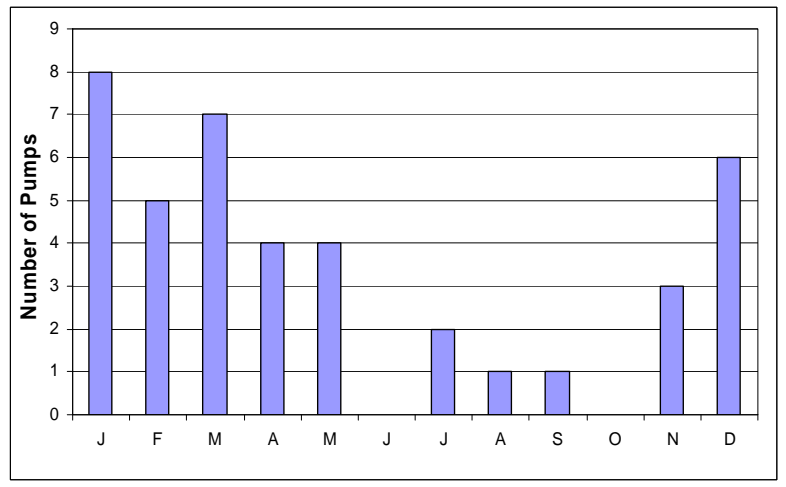

Figure 4. Number of pumpings by month, "pump when full" management plan

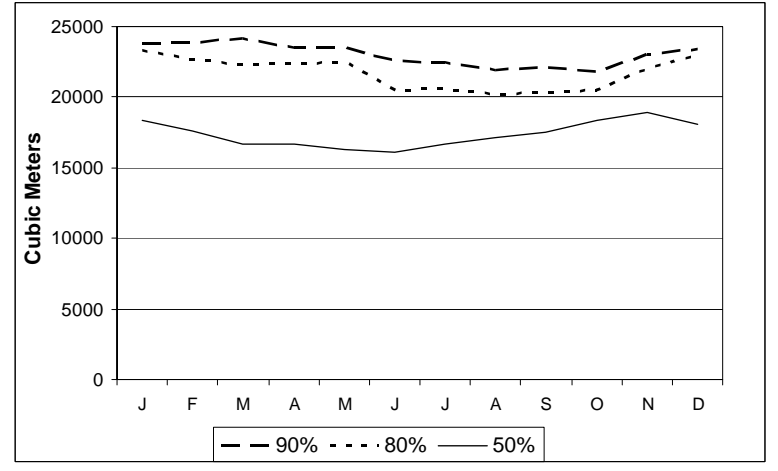

Figure 5. Probable volume, first of each month, three levels, "pump when full" management plan

environment and the plants can not use the water or the nutrients. Figure 5 shows the probable volume of waste in lagoons is high at the wrong time, considering water balance of soils and plant need for water and nutrients. This information is displayed at the $90 \%, 80 \%$, and $50 \%$ probability levels. These probabilities of volume are quantitative indicators of risk that pumpings will be required at the wrong time of year under this management scheme. Each pumping under this plan should also be considered an emergency pumping since an imminent overflow will be prevented by the pumping.

In order to address the problem of mis-timing between demand and supply of wastewater for land application, simulations of the "fixed date" pumping strategy were analyzed. Figure 6 compares the numbers of emergency pumpings required under each of the "fixed date" plans with those required under the "pump when full" plan. It can be seen that these management plans increase the total number of pumpings required (Figure 7). However, all of the pumpings (emergency and planned) conducted under each of the four "fixed date" plans come between April and August, solving the problem of supply and demand for the wastewater still prevalent in the "pump when full" plan. These results show that no overflow occurred and no lagoons had to be pumped outside the growing season in any of the four 45-year simulations.

Figure 6 summarizes the impact of management decisions to pump on specified dates on the supply and demand problem in land application of swine waste. It can be seen that changing the date of pumping progressively shifts the period of maximum lagoon volume further and further into the growing season. Therefore, management by controlled and pre-selected pumping dates offers a clear solution to the hydrologic aspects of the supply and demand problem of waste disposal inherent in the region's climate. A final decision on the most appropriate fixed pumping date for a specific production facility should include consideration of nutrient need and uptake potential of 
particular crops as well as economic aspects of the slight increase in number of pumpings resulting from this management plan.
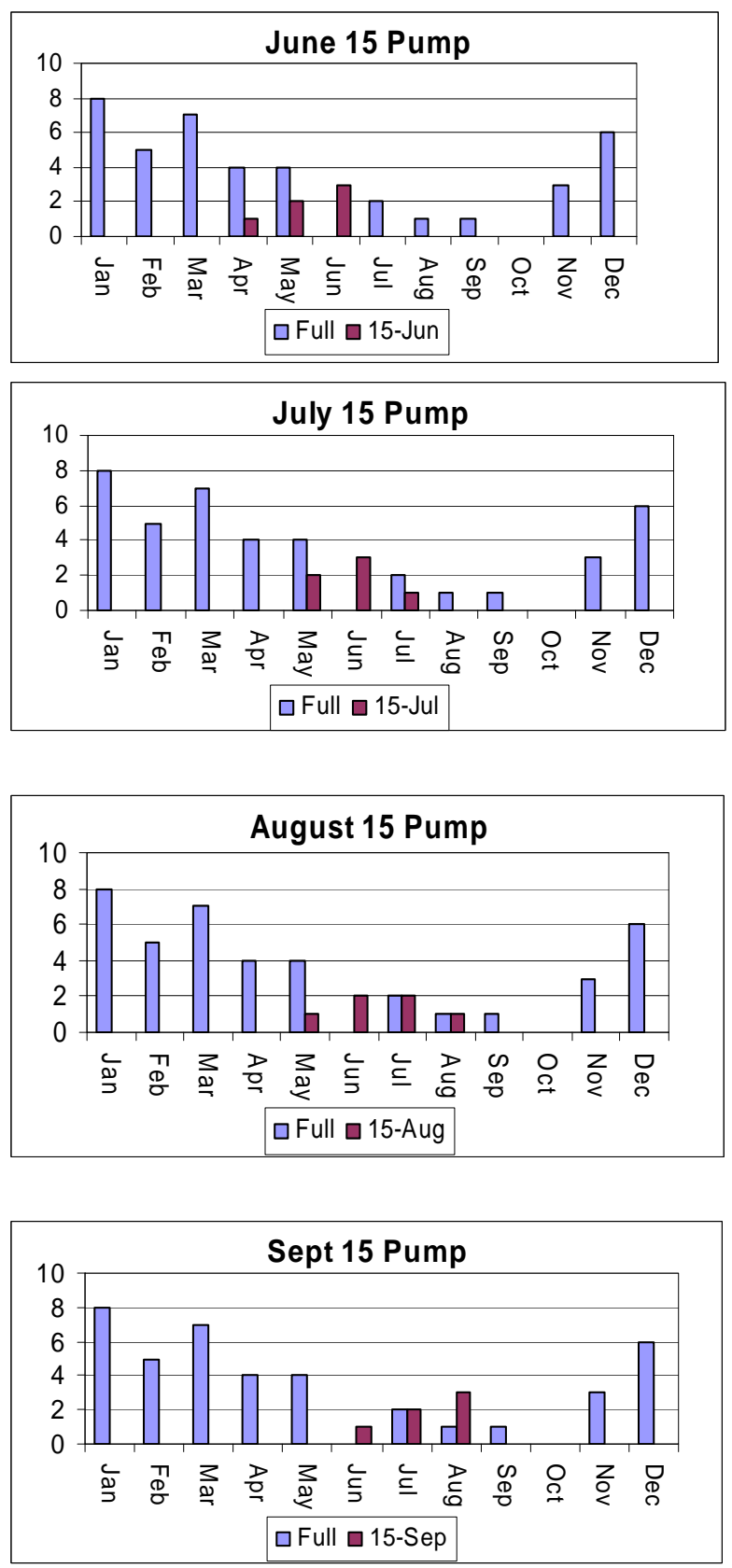

Figure 6. Number of emergency pumpings, "fixed date" plans vs "pump when full" plan

\section{Summary and Recommendations}

Using the 45-year daily simulation of a swine disposal lagoon operation, several characteristic aspects of such operations in the southern region became evident:

1) demand for the wastewater (hydrologically and agronomically) is highest in the growing season;

2) availability of the wastewater to meet the demand is highest in the winter and spring, creating an offset distribution;

3) using the simplest management scheme ("pump when full") minimizes the number of pumpings required but amplifies the time distribution problem created by the natural climate regime;

4) using the "fixed date" management scheme allows a shifting in time of the supply of wastewater so that it matches the demand of the crop and the climate for nutrients and water, solving the time distribution problem; and

5) selection of the optimum pumping date can vary according to type of crop used and economics of pumping.

It is recommended that maximum advantage of the climate regime in disposal of swine wastewater can be gained by use of the September 15 "fixed date" pumping plan. Figure 8 shows that this management scheme completely shifts the volume of available wastewater into the growing season, in direct opposition to the "pump when full" scheme. Assuming no overriding agronomic or economic constraints to adoption of this date, pumping every September 15 seems to be the optimum management plan for swine operations in the southern climate region.

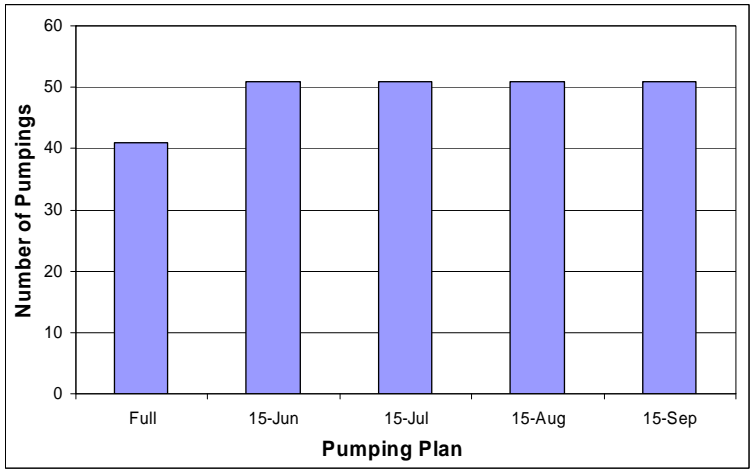

Figure 7. Total number of pumpings under different management plans, 1961-2005 


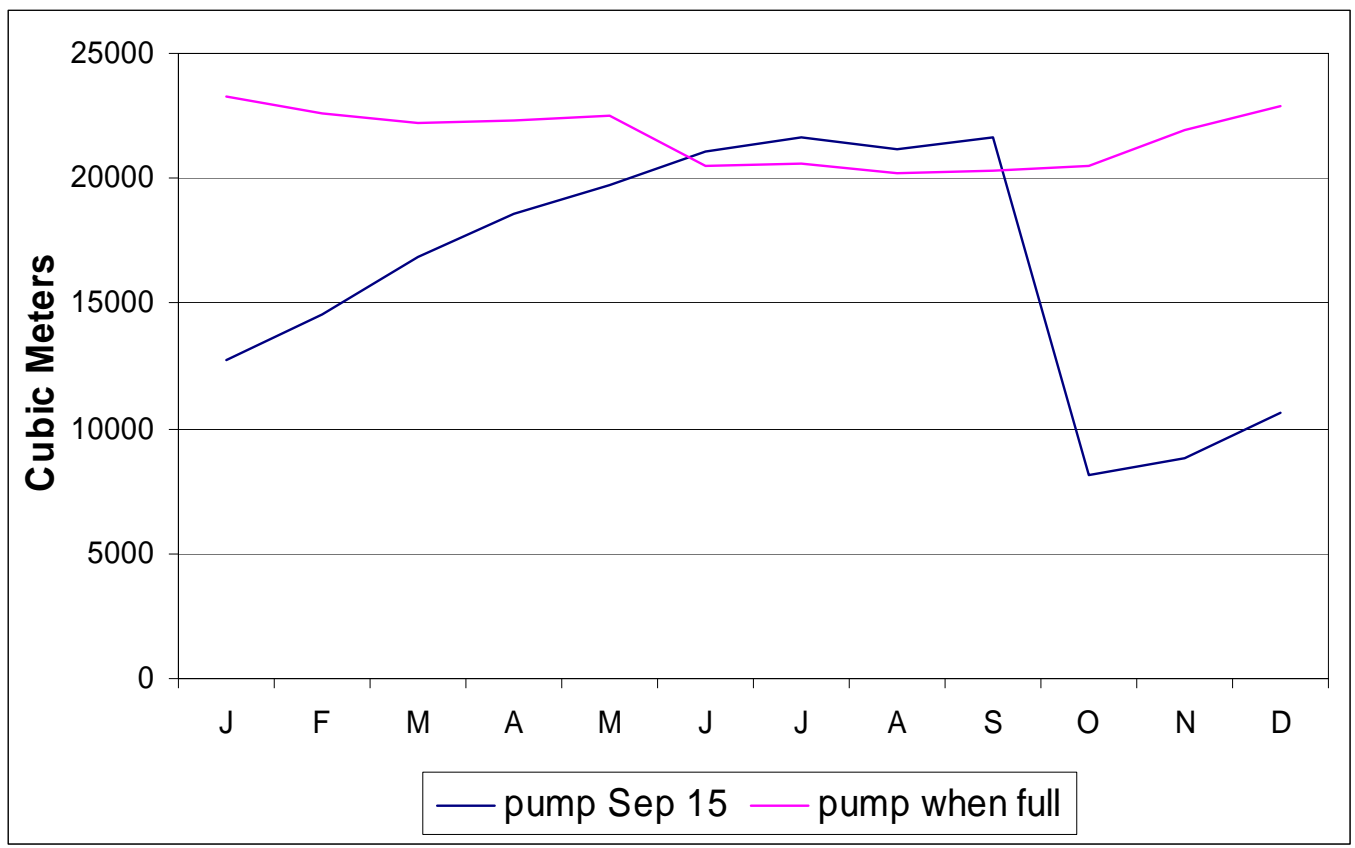

Figure 8. Probable volume, first of each month, $80 \%$ level, "September $15^{\text {th }}$ fixed date" plan vs "pump when full" plan, showing shift of available wastewater volume

\section{References}

Al-Omari, K.A., 1989: Stochastic Design of Wastewater Storage for Land Application. M.S. Thesis, University of Cincinnati Department of Civil Engineering, Cincinnati, $\mathrm{OH}$.

Barbarick, K.A., B.R. Sabey and N.A. Evans, 1982: Application of Wastewater Effluent of a Rural Community to a Mountain Meadow. Journal Water Pollution Control Federation, 54(1), 7076.

CAST, 1996: Integrated Animal Waste Management. Council for Agricultural Science and Technology. Ames, IA.

Cathcart, T.P., C.L. Wax, J.W. Pote and Sugeng Triyono. 2007: A Climatological Basis for Conserving Groundwater and Reducing Overflow in Aquaculture Ponds in the Southeast United States. Aquacultural Engineering, 36, 225-232.

Deese, P.L. and J.F. Hudson, 1980: Wastewater Management Facilities for Small Communities. U.S. Environmental
Protection Agency, Washington, DC, 17 pp.

Environmental Defense, 2002: Fact Sheet: Animal Factory Farms. November 2002.

Loehr, R.C., 1984: Pollution Control for Agriculture, 2nd Edition, Academic Press, Inc. 383 pp.

Mancino, C.F. and I.L. Pepper, 1992: Irrigation of Turf with Secondary Sewage Effluent: Soil Quality. Agronomy Journal, 84:650-654.

Martin, J.G., III, 1995: Waste Management Options to Meet New Environmental Regulations. Gainesville, FL.

Midwest Plan Service, 1985: Livestock Waste Facilities Handbook (MWPS-18), 2nd Edition, Iowa State University, Ames, IA

Natural Resources Conservation Service, U.S. Department of Agriculture, 1996: 
Worksheet for Waste Treatment

Lagoon. Form \#MS-ENG-359 (Revised 1-96).

Natural Resources Conservation Service, U.S. Department of Agriculture, 1993: Waste Utilization Worksheet. Form \#MS-ENG-633 (Revised 6-93).

Palazzo, A.J. 1981: Seasonal Growth and Accumulation of Nitrogen, Phosphorus, and Potassium by Orchardgrass Irrigated with Municipal Wastewater. Journal of Environmental Quality, 10, 64-68.

Pote, J.W. and C.L. Wax, 1995: Climatic Criteria for Land Application of Municipal Wastewater Effluent. Water Research, 29, 323-328.

Thoma, K., P.A. Baker, and E.B. Allender, 1993: Design Methods for the Development of Wastewater Land Disposal Systems. Water-Sci-TechnolJ-Int-Assoc-Water-Pollut-Res-Control. Oxford: Pergamon Press, 27, 77-86.

Schwab, G.O., R.K. Frevert, T.W. Edminster, and K.K. Barnes, 1981: Soil And Water Conservation Engineering, 3rd Ed. John Wiley and Sons, New York. 525 pp.

Wax, C.L. and J.W. Pote, 1996: Influence of Climate on Design of Systems for Land Application of Wastewater. Climate Research, 6, 71-78. 


\section{Non-technical Service Summary}

\section{Climate service question}

Can a management program be developed for land application of swine waste water that accounts for and overcomes the natural climatic pattern in which timing of the supply of water to be disposed of and the water-consuming capabilities of plants, the atmosphere, and soil are out of phase?

\section{Background information}

Disposal of wastewater from swine production is becoming an increasing problem as production facilities increase and regulations governing disposal become more restrictive. Effective systems utilizing a lagoon with the land application of wastewater depends on evaporation, infiltration into the soil, and on a crop's ability to uptake nutrients at the time of discharge. Climatic characteristics in many ways dominate the operation of land application of waste water. In a land application system the level of the storage lagoon rises during periods of precipitation as the soil becomes wet and the net water requirement of plants decreases, inhibiting or preventing the pumping of wastewater. Conversely, during periods of clear weather evaporation increases, the soil becomes dry, and the water requirements of plants are immediate, allowing and enhancing the efficiency of the land application system of disposal.

Irrigation is the predominant method of choice for land application, even for municipal wastewater (Deese and Hudson 1980). However, those municipal systems are designed for daily irrigation of effluent when possible (Pote and Wax 1995). The Natural Resources Conservation Service of the U.S. Department of Agriculture (NRCS) designs swine lagoon irrigation systems for pumping of the wastewater as seldom as once a year (NRCS 1996, 1993).

Poor management decisions and methods may result in long-term, chronic problems related to nutrient disposal, and short-term dramatic failures with the lagoon and land application. For example, lagoons too full during the winter season are faced with only two undesirable and potentially hazardous alternatives: a catastrophic spill event, or a forced pumping at a time when neither the atmosphere nor the soil can accept the water, and plants can not take up nutrients.

\section{Methodology}

Daily precipitation (P) and pan evaporation (E) data from State University, Mississippi were obtained from observations of the Cooperative Network of the National Weather Service. This location was representative of the southern region climate and had the most complete record of the climatic elements needed for the simulation. A factor of $0.8 \mathrm{E}$ was used to correct measured $\mathrm{E}$ to a more realistic estimate of evapotranspiration losses (ET) from small bodies of water or lagoons (Schwab, et al. 1981).

Daily computation of water entering the lagoon as precipitation (P) and waste flow (W) and leaving as evaporation (ET) or pumping for land application (A) was conducted for the 45-year period 1961-2005 to simulate the operation of a lagoon. Cumulative summation of these daily 
values $(\mathrm{P}-\mathrm{ET}+\mathrm{W})$ provided patterns of water volume in the lagoon. Simulations were conducted to evaluate lagoons that were allowed to overflow in lieu of planned pumping (representing a "no pump" management system), and that were managed with five management schemes (pump when full, pump every June 15, July 15, August 15, and September 15). These six management plans were evaluated based upon the number of required pumpings and the seasonal timing of the pumpings.

\section{Results}

The no pump management scheme resulted in an average annual uncontrolled overflow of $13,945 \mathrm{~m}^{3}$ of wastewater. The pump when full management plan resulted in 41 total pump events over the 45 year period, overwhelmingly occurring during the winter months when nutrient uptake and evaporation are low. The most climatically effective management plan was found to be the planned date pumping schemes. Management with each of the four planned dates strategies resulted in 51 total pumping events over the 45-year period (10 more than the pump when full plan) but provided the greatest potential for nutrient uptake and water use with all planned and emergency pumpings occurring during the summer season only.

Any of the planned date pumping strategies will accomplish the objective of moving the disposal of waste water to the time of year when land application is effective, thus taking advantage of the regional climatic characteristics. If there are no specific agronomic or economic considerations to the contrary, adoption of the September $15^{\text {th }}$ planned pumping is recommended to swine producers in the southern region, because this plan moves all emergency pumpings furthest into the growing season when land application is most effective. For producers to use this management plan no capital investment is necessary - the producer must only make a management decision to pump each September $15^{\text {th }}$. 